\title{
From Policy and Response to System Design and Operations: Inter-Governmental Transit Security Planning in the U.S.
}

\author{
Camille N.Y. Fink, Brian D. Taylor, and Anastasia Loukaitou-Sideris \\ UCLA Institute of Transportation Studies
}

\begin{abstract}
The events of September 11th, 2001, brought the issue of transportation security and terrorism to the forefront of civil society. Transit security is especially challenging because of the nature of transit systems as open and accessible public places and the need to keep these systems running quickly and efficiently; transit officials cannot employ many of the security strategies used in aviation security. This paper examines the recent developments in transit security planning in the U.S. using two sources of data: 1) interviews with officials from federal agencies, a national transit industry organization, and local transit agencies, and 2) a nationwide survey of transit operators. The findings show that transit security remains a major concern for operators who must work to balance security needs with operations and management goals. Interagency coordination has become a crucial element of security planning. In addition, environmental design and public outreach and education - two strategies that received much less attention pre-September 11 th-have emerged as much more important in transit security planning.
\end{abstract}


(CNN) - U.S. mass transit systems were put on higher alert after Thursday's bombings in London, with officials in major cities urging Americans to go about their business but be on the lookout for anything suspicious... New York Police Commissioner Ray Kelly told CNN his officers were "doing everything that's prudent, everything that we reasonably can do to protect the city." But he said it was impossible to put a police officer "on every train all the time, or one on every station all the time." [http://www.cnn. com/2005/US/07/07/us.response/; posted Thursday, July 17, 2005, 11:41 pm EDT (03:41 GMT)]

\section{Overview}

The events of September 11th, 2001, brought the issue of transportation security and terrorism to the forefront of civil society. Subsequent attacks-on subways in Moscow and Madrid and, more recently, on the Underground and bus networks of London-have further highlighted terrorism as a global threat with public transit systems as primary targets. While transportation security officials have long been aware of the possible threat of terrorist attacks on transportation networks, these tragic events revealed both vulnerabilities in security systems and the unimaginable consequences of such breaches. Public surface transportation systems are, in general, easy and effective targets for terrorists; this fact is reflected in the relatively significant proportion of attacks occurring on these systems. In 1991, transportation systems were the target of 20 percent of all violent attacks. This rose to almost 40 percent in 1998 (Boyd and Sullivan 2000). In addition, an examination of the public system targets and tactics used worldwide by terrorists from 1920 to 2000 shows that the largest percentage (46\%) of terrorist attacks against public surface transportation systems was carried out on subways and trains, subway and train stations, and rail (Jenkins 2001).

The vulnerability of public transit systems lies in the fact that they are very open and accessible, with fixed, predictable routes and access points. Their openness and anonymity make it easy for potential terrorists to hide in crowds without arousing suspicion. Securing such open and public systems presents transit and security officials with daunting challenges. The volume of passengers makes it impossible for transit operators to employ the types of security tactics used in commercial aviation. Closed system security measures, such as the screening of passengers and luggage with X-ray machines and metal detectors, hand searches, passenger profiling, dog sniffers, armed guards, and the like, would lead to intoler- 
able delays and costs (Balog, Devost, and Sullivan 2002; Jenkins 1997; Boyd and Sullivan 1997).

Attractive, convenient public transit systems help to mitigate many of the problems of widespread auto use and provide mobility for those who do not have regular access to automobiles, including youth, the elderly, the disabled, and poor people. Security measures that cause inconvenience, delay, or added cost to travel by public transit are likely to shift travelers and cities toward greater dependence on private vehicles. Given that many transit systems around the U.S. struggle to control costs, maintain a market share of metropolitan trips, and secure and maintain stable sources of public subsidy, security measures that diminish the accessibility, convenience, and/or affordability of transit service conceivably could threaten the viability of public transit in many places. On the other hand, security measures that serve to increase the general safety, attractiveness, and reliability of transit systems without seriously compromising their accessibility are likely to enhance the attractiveness of public transit to potential riders (United States General Accounting Office 2002). Thus, while policing, surveillance, and emergency response will likely remain central to transit security planning, weaving security planning into transit system design and operations in ways that increase the safety and attractiveness of transit service offers potentially significant benefits to transit systems and their customers.

\section{This Study}

While most decisions about transit services (routing, headways, fares, etc.) are entirely local, security planning requires transit agencies to work closely with local law enforcement as well as federal transportation and security officials. Such ongoing inter-governmental collaboration, particularly with federal security officials, is new territory for many transit managers. This paper examines the fruits of this collaboration since September 11th, with a particular focus on how security considerations are being incorporated into the planning, design, and operations of U.S. transit systems.

Our data for this analysis are drawn from two sources. The first is interviews conducted either face-to-face or by telephone with officials from a number of federal and transit agencies and a transit industry organization; each interview lasted approximately one hour and involved an open-ended question format. At the federal level, we spoke with officials from the Department of Homeland Security 
(DHS), the Transportation Security Administration (TSA), the Federal Transit Administration (FTA), and the Federal Railroad Administration (FRA). We also conducted interviews with representatives from the American Public Transportation Association (APTA) and senior staff with several major transit operators, including the New York Metropolitan Transportation Authority (MTA), Amtrak, and two other transit agencies that asked to remain anonymous. The geographic focus of these interviews was the northeastern U.S. We selected this region for three reasons. First, the cities of the northeastern U.S., and in particular the New York metropolitan area, are home to, by far, the largest and most heavily patronized networks of public transit systems in the country; metropolitan New York alone accounted for 39 percent of all transit trips taken in the entire U.S. in 2002 (American Public Transportation Association 2004). Second, while the venue of the September 11th attacks was the air transport system, their effect on New York's, and, to a lesser extent, Washington's, public transit systems was dramatic and long-lasting and profoundly tested the ability of transit staff in these two cities to respond to a major crisis. Finally, as the seat of the national government, most federal transit and transportation security officials are in the Washington, D.C. area.

Where appropriate, the findings from these interviews are supplemented with the results of a 2004 nationwide survey of all 259 U.S. transit agencies that (according to the National Transit Database maintained by the Federal Transit Administration) operate at least 50 vehicles in peak period service. The letter to each general manager asked her/him to designate the appropriate person or persons to complete an on-line survey. All told, respondents from 113 transit agencies completed survey questions, for a 44 percent response rate. ${ }^{1}$ This survey follows two earlier surveys of transit operators: 1 ) a survey of 42 transit managers that took place several years before September 11th (Boyd and Sullivan 1997) and 2) a United States General Accounting Office (GAO) study conducted soon after September 11th that included a survey in 2002 of officials at 155 U.S. transit agencies (2002). This latter survey-based report considered the roles the federal government should play in helping public transit operators reduce both the likelihood and impacts of terrorist attacks on U.S. transit systems. 


\section{Findings}

\section{Despite nearly four years of relative quiet, most transit agency secu- rity staff remain extremely concerned about the possibility of transit terrorism on their systems.}

Chief John O'Connor of the Amtrak Police Department at Penn Station believes that the threat of terrorism on transit systems is "very real and that it is a question of when rather than if." For O'Connor, September 11th was a galvanizing force, but it had started to fade somewhat in the mind's eye of the public. The events in Madrid in March 2004, however, brought the issue of transportation security back to the forefront and, according to O'Connor, "now for most transit agencies it's one of their top priorities, if not the top." Officials are especially concerned about the negative publicity transit has received as a high-profile terrorist target after the recent attacks in Moscow, Madrid, and London. Attention is increasingly focused on rail systems and major stations, such as Penn Station and Grand Central Station. These large multimodal facilities and landmarks are considered potential targets of particular concern.

Indeed, respondents to our nationwide survey believed heavy (80\%), commuter (63\%), and light rail (60\%) to be "very vulnerable" to future attack, while less that half believed bus service (45\%), paratransit service (26\%), and ferry service (22\%) to be very vulnerable. With respect to transit system components, tracks and lines (66\%) and stations (63\%) were most likely to be identified as "very vulnerable."

Greg Hull is Director of Operations, Safety, and Security Programs for the American Public Transportation Association (APTA), a transit industry organization with a membership of over 1,500 transit agencies and business representatives from across the U.S. In terms of understanding the transit terrorism threat at the local level, he acknowledges that perspectives on the level of risk and threat vary widely. However, he argues that the threat is pervasive regardless of whether the transit system is located in a large metropolitan area or a small one:

Some of us might argue that it doesn't matter where you are. I mean, look at Oklahoma City. This isn't just Al Queda we're dealing with. There are domestic terrorists, there are people who have political missions, there are people who are wackos, there are people who are copycats, and so it doesn't matter, from my perspective, it doesn't matter where you are located, whether in Pocatello, Idaho, or Washington, D.C.... It doesn't matter what city you live in or what town you live in, there is a need to address these issues. 
Hull also asserts that agencies need to address requirements in all modes-from subways to buses-contending that transit terrorism is not confined to the largest population centers. However, he acknowledges that, practically and realistically, when making decisions about security using a risk management approach, local agencies do consider large numbers of people to pose the greatest vulnerabilities.

\section{Increased intra-agency coordination is important in transit security planning and interagency coordination at the national and interna- tional levels is crucial.}

Several interviewees noted the importance of having management, planning, and operations personnel work hand-in-hand with police and security staff to both minimize security-related service disruptions and to avoid having such disruptions become safety hazards in their own right. Said one interviewee,

As the security people come up with ideas that may not fit, if you have operating people sitting there, that's better. We have to reach some sort of a balance, some sort of a medium. How do we stop trains, how do we do inspections, but weave it into the regular fabric of our operations so our customers hardly notice? If we have a suspicious package, what is the procedure to deal with it? We try to minimize the delay to the train while still answering the concern, because when you start delaying trains, you create another safety problem as more trains get backed up. Now you're creating a service disruption. In Penn Station or Grand Central, many of the subway stations where they have such volumes, just delaying a train or two, you can lose a station. We end up having to shut down things. And then you get thousands and thousands of people in a panic situation wondering, "What's going on? Why am I being evacuated?" Once you can't run trains, you can't let people into the station because you have a crush load.

FTA's assistance to local transit agencies is aimed at trying to standardize practices and provide support such that the agencies are prepared and can share information among themselves. The goal is to identify best practices and their dissemination to other agencies in similar circumstances. A high level of interagency cooperation already has been established in some places; transit security officials in New York describe a significant amount of coordination not just in the New York area, but in the Northeast corridor more generally. O'Connor of Amtrak says that his agency deals with the Massachusetts Bay Transportation Authority (MBTA) in Boston, the Connecticut Department of Transportation, the Long Island Railroad, New Jersey Transit, the Southeastern Pennsylvania Transportation Agency 
(SEPTA), and the Maryland Rail Commuter (MARC). Some of these agencies have their own police departments, while others do not; some agencies provide security services for other transit systems. In a place such as Penn Station, there is a multijurisdictional structure where the station is owned by Amtrak, which patrols the majority of the facility. Long Island Railroad leases a portion of the station and the New York MTA police patrol the lower level. Finally, the street level and subway entrances are policed by the New York Police Department (NYPD). Coordination among these policing and transit agencies becomes imperative.

Hull also emphasized that agency coordination and the dissemination of information are crucial. Very few people in the transit industry, even among the police forces, have security clearances. According to Hull, after September 11th, APTA realized that the transit industry and federal transportation agencies needed to access security intelligence information. Transit agencies in major cities had good working relationships with the Federal Bureau of Investigation (FBI) through established joint terrorism task forces. However, this was not the case across the board. The U.S. Department of Transportation (USDOT) designated APTA a sector coordinator for the establishment of a Public Transit Information Sharing Analysis Center (PT-ISAC), part of the larger umbrella Surface Transportation ISAC. In this role, APTA has served as the primary contact for organizing public transportation agencies around security issues. APTA worked on this PT-ISAC project through an FTA grant. Hull says that APTA used the grant to contract with a company based in Virginia:

They have on staff those people who have backgrounds, past careers with the FBI and Department of Defense. They have top-level security clearances. And they are able to glean through sources of information and package it in a manner that's meaningful to the transit industry. We are now in the process of connecting all transit agencies within this ISAC to be able to access this information.

Hull related that the flow of information is from the ISAC out to transit agencies, but there is also a push to have agencies input their own information into the intelligence system: "If an agency experiences a certain degree of trespassing, they might see that as kids getting into the train yards or something. But maybe it's part of something that's more of a trend in the industry and that becomes good information that needs to be analyzed and disseminated out to the industry."

Hull says the direct exchange of information among agencies is also a priority for APTA and something it helps facilitate: 
We get the permission of the transit agencies to share whatever the best practice might be. It might be something like preventive maintenance, it might be a design concept in a facility, it might be the way that staff are utilized for safety and security. Our industry has historically and continues to be very supportive of one another. One of the things that has occurred is that where prior to 9/11 we saw more agencies more willing to share their security plans, now that's a little more closely guarded. They may share those plans with one another, but it would be eye-to-eye and hand-to-hand as opposed to what we may have seen in prior years. But there's a very, very open sharing of information within the system.

In addition, APTA has actively engaged individuals in various federal agencies working on security issues, particularly DHS and TSA, in order to educate them about public transit. According to Hull, APTA has used a Transit 101 presentation with the message that the organization-not the federal government-has the real expertise in transit. APTA involves the transit industry in all important stages of planning:

They [the federal government] may have the expertise in terms of security development for certain perspectives and certainly they have the funds and the legislative mandate. But the bottom line is that if there are any directions or mandates to the transit industry.... the only way that those things can be successful is by engaging us at a very early stage so that the industry can have proper buy-in and actually have a hand in the development of any such standards that might come forward.

Hull understands that transit security is happening in an international context. As such, the organization has formal partnerships with other transit industry groups around the world: the Canadian Urban Transit Association, the International Association of Public Transport (UITP, with headquarters in Brussels), the Latin-American Association of Underground Networks and Subways (ALAMYS), and the Cooperation for the Continuing Development of Urban and Suburban Transportation (CODATU), based in Paris and representing transit systems in developing nations. A couple of years ago, APTA invited these associations and some of their primary agency members to meet with them in Washington. The goal was to share information about program development and relationships with government agencies. APTA representatives continue to share information with these other groups and they invite each other to special conferences and workshops on security. 


\section{Balancing the security of their systems with other operations and management objectives is a central dilemma for many transit man- agers.}

Particular security strategies, like inspecting passenger bags or employing explosives detection technologies, pose enormous challengers to transit systems that depend on operating as quickly and reliably as possible. Some officials, like Amtrak's O'Connor, are sanguine that improved security and efficient operations can be effectively integrated to bolster ridership: "If people do not feel safe and secure, they won't use the system. They'll avoid it if possible. If you allow the system to fall into disorder and decay, it will definitely affect your ridership." Thus, operators are aware that weighing the costs and benefits of system security overall, as well as of particular measures, is a complex process and includes variables that can be difficult to quantify. An overwhelming majority (87\%) of the respondents to our nationwide survey of transit operators reported that anti-terrorism efforts were either fully (46\%) or partially (41\%) congruent with anti-crime efforts.

Amtrak's O'Connor believes that all security strategies are important, and the distinction is between short term and longer term strategies:

On a day to day basis, your focus is on operations, police deployment, both prevention and response. Long term, you need to set goals and design activities to help achieve those goals. You need to plan long term capital improvement that will help you achieve those goals. And you have to constantly-daily, weekly, quarterly, yearly-measure the effectiveness of your strategies and tactics to see if they are in fact achieving those goals.

Threat and vulnerability assessments are one important tool to help security officials weigh their different options, and, in fact, 80 percent of our survey respondents reported that they conducted the most recent threat and vulnerability assessment at their agencies to identify effective security technology and procedures. These assessments are also quite common. Eighty-five percent of the 113 agencies surveyed nationwide indicated that they have conducted some level of threat and vulnerability assessment; agencies with rail were much more likely to conduct a comprehensive assessment than other agencies. This is a significant increase over the 54 percent reported by respondents to the 2002 GAO survey (United States General Accounting Office 2002).

Survey respondents were asked to describe other ways their agencies have attempted to identify and assess security vulnerabilities in the transit system. 
Methods identified most frequently were constant monitoring of crime statistics, periodic reviews/discussions of security by employees, daily visual checks/observations, employee and customer feedback, and regular contact with local law enforcement agencies. Many agencies reported having an internal security committee that meets on a regular basis to discuss and monitor security. One agency reported an active Transit Watch program, which solicits the participation of customers to point out vulnerabilities.

\section{The perceived relevance of environmental design as a security strat- egy increased significantly after September 11th.}

All of the transit officials interviewed for this research believe that design elements are central to security planning and should be explicitly addressed during the design and construction of facilities. Said one interviewee, "We've now incorporated security in the designs and boilerplates. Whereas at one time if you were going to construct a station, you would have only had to do safety-fire suppression, fire and life safety, ventilation, lighting, fire alarms. But now there's a security piece that gets incorporated." Several of those interviewed suggested that, by including security as an integral part of the design process, transit agencies can avoid costly and sometimes problematic station retrofits and redesigns.

The officials interviewed reported implementing other, less expensive environmental design strategies since September 11th, including removing trash cans, locking down seats in rail cars, taking out recessed telephones, eliminating nooks and crannies at stops and in stations, and installing access controls on all doors. Such strategies-both elaborate and simple-often are grouped under the rubric of "crime prevention through environmental design," or CPTED. Among the 113 respondents to our nationwide survey of large and medium-sized transit operators, 58 percent reported that their agency now makes moderate or extensive use of CPTED strategies. About half ( $49 \%$ ) of bus-only agencies reported using CPTED strategies; among transit agencies operating one or more rail modes, which are far more likely to include enclosed stations, the figure was closer to 9 out of 10 (88\%).

While extensive design retrofits for existing stations would be costly, certain design schemes means can be utilized to enhance security. Amtrak's O'Connor says that, after September 11th, his agency took several steps to put environmental design features into place. At the major stations, barricades and CCTV systems were installed without making major renovations to any of the stations. O'Connor pointed to the Washington, D.C. Metro system as one of the best in terms of 
security-oriented environmental design, with its clear sight lines and relatively few nooks and crannies. With respect to the future, O'Connor suggests that intercity transportation agencies will have to consider creating "secure zones," where people are screened and their bags checked before they enter boarding areas. He acknowledges, however, that this type of system is difficult to implement in intracity transit environments where very large numbers of people make relatively short trips.

\section{Most transit officials believe that passenger outreach and awareness strategies are important.}

Many transit systems internationally-such as the Underground subway system in London-have actively sought to enlist the help of patrons in watching for and reporting suspicious activity. William Morange, Executive Director for Security at the New York MTA, believes that rider and employee awareness is the most effective transit security strategy. He notes that the Executive Director of New York MTA put an "if you see something, say something" program in place before September 11th, "where if you see something that's not kosher-the way it should look-report it to the conductors, report it to the motormen. . . Now calls are going up, but it's worth it for us."

APTA's Hull says that there are "tools that enhance security and we certainly see more of the transit agencies moving towards introducing a variety of technologies," but he emphasizes two particular security strategies: (1) training and (2) emergency preparedness drills. The former includes the formal training of transit staff, but also outreach to transit customers-"the whole concept of having a broad network of eyes and ears and voices that will look for and let us know when they see something that just doesn't seem right."

When asked about information and outreach strategies to educate transit riders about general emergency and safety issues, three-quarters of those surveyed from rail systems report having such programs in place, and 90 percent of these include specific strategies to educate transit riders about dealing with terrorist attacks. In addition, while fewer than 30 percent of respondents to our national survey of transit operators perceived public education and user outreach as "central" or "significant" to increasing transit security prior to September 11th, this figure jumped to over 60 percent after September 11th. 


\section{Conclusions}

In this paper we have examined, through both in-depth interviews and responses to a national survey, efforts of federal agencies and national organizations in the U.S. and transit operators (primarily in the large cities of the northeastern U.S.) to maintain and enhance the security of local rail transit system design and environments. Our findings show that transit security has emerged as a significant concern for transit operators, especially after recent terrorist attacks on systems in Madrid, Moscow, and London. Although policing and security hardware and technology continue to be primary security strategies, the incorporation of environmental design and public education and user outreach programs has increased substantially since September 11 th. Agencies continue to struggle with the conundrum central to transit security planning-effectively securing their systems while keeping the system running efficiently. In this regard, transit operators are constantly assessing their security options and understanding the ways in which system security can help or hinder ridership.

One of the important developments in transit security is the amount of cooperation that appears to be occurring among federal, national, and local agencies. Federal interviewees were unanimous in their view that relatively little in the way of "turf battles" was occurring as agencies juggle their evolving and, in some cases, newly acquired roles and responsibilities. The contributions of non-governmental industry organizations, particularly APTA, deserve special mention in this regard. APTA has assisted each of the organizations mentioned in this paper in a variety of ways, including cooperation in the development of the PT-ISAC, which facilitates the sharing of security-related information among transit and government agencies. APTA and transit operators in the U.S. also seem eager to foster these relationships both in the domestic and international contexts. As to the ultimate effectiveness of these many efforts to increase transit system security, only time will tell. 


\section{Appendix-List of Interviews}

Hull, Greg. Interview by Camille Fink. American Public Transportation Association, Washington, D.C., 14 January 2004.

Morange, William. Interview by Ellen Cavanagh. Metropolitan Transportation Authority, New York, NY, 4 June 2004.

O'Connor, John. Interview by Ellen Cavanagh. Amtrak Police Department, Penn Station, New York, NY, 1 June 2004.

The interviews of security officials at two other transit agencies informed the findings reported here, but the identities of the people interviewed, their organizations, and any agency-specific information from these interviews are not reported here to honor their requests for anonymity.

\section{End Notes}

${ }^{1}$ Both the interview and survey data are drawn from a larger transit security study entitled "Designing and Operating Safe and Secure Transit Systems: Assessing Current Practices in the U.S. and Abroad" undertaken by the paper's authors and a group of other researchers at UCLA, UC Berkeley, and San Jose State University. 


\section{References}

American Public Transportation Association. 2004. Transit agency data. American Public Transportation Association 2004 [cited 2004]. Available from http:// www.apta.com/research/stats/.

Balog, John N., Matthew G. Devost, and John P. Sullivan. 2002. Public transportation security, Volume 1: Communication of threats: A Guide. Washington, D.C.: National Academy Press.

Boyd, Annabelle, and John P. Sullivan. 1997. Emergency preparedness for transit terrorism. In TCRP Synthesis 27. Washington, DC: National Research Council.

Boyd, Annabelle, and John P. Sullivan. 2000. Emergency preparedness for transit terrorism. TR News 208.

Jenkins, Brian Michael. 1997. Surface transportation systems and patrons from terrorist activities. San Jose: Norman Y. Mineta International Institute for Surface Transportation Policy Studies.

Jenkins, Brian Michael. 2001. Protecting surface transportation against terrorism and serious crime: An executive overview. San Jose, CA: Norman Y. Mineta International Institute for Surface Transportation Policy Studies.

United States General Accounting Office. 2002. Mass transit: Challenges in securing transit systems. In Testimony Before the Subcommittee on Housing and Transportation. Committee on Banking, Housing, and Urban Affairs, U.S. Senate.

United States General Accounting Office. 2002. Mass transit: Federal action could help transit agencies address security challenges: General Accounting Office.

\section{Acknowledgements}

This research was funded by grants from the Mineta Transportation Institute at San Jose State University and the International Institute at UCLA. Thanks in particular to Rod Diridon and Trixie Johnson at the Mineta Transportation Institute and to Geoff Garrett at the International Institute for their support and encouragement of this research.

In addition to the authors, three people contributed importantly to this article. Professor Peter Haas of San Jose State University conducted a number of additional 
interviews with U.S. federal transportation security officials related to the issues presented in this paper. Professor Robin Liggett analyzed the survey data reported on here. Norman Wong of the UCLA Institute of Transportation Studies helped to design and execute the survey and, in addition, assisted with the production of this paper. Thanks also to the other members of the "Designing and Operating Safe and Secure Transit Systems: Assessing Current Practices in the U.S. and Abroad" research team: researchers Ellen Cavanagh (UC Berkeley), Christopher Cherry (UC Berkeley), Rachel Factor (UCLA), Babak Hedjazi (UCLA), Kimiko Shiki (UCLA), and Martin Wachs (UC Berkeley) and project advisory committee members Annabelle Boyd, Frances Edwards, Greg Hull, Brian Jenkins, John Sullivan, and Amy Zegart.

Finally, our heartfelt thanks to all the transit managers, chiefs of security, planners, and architects who took time to share their thoughts and opinions in our interviews and survey.

\section{About the Author}

Camille N.Y. Fink (cnyfink@yahoo.com) is a Ph.D. student in the UCLA Department of Urban Planning. Her interests include transportation safety and security; transportation equity; qualitative methods in transportation; and race, gender, and the built environment. Before returning to graduate school, she worked in radio broadcasting and for a homeless advocacy coalition in the Bay Area. She has a B.A. in Sociology from UC Davis and an M.A. in Urban Planning from UCLA.

Brian D. Taylor (btaylor@ucla.edu) is an Associate Professor and Vice-Chair of Urban Planning and Director of the Institute of Transportation Studies at UCLA. His research centers on both transportation finance and travel demographics. He has examined the politics of transportation finance, including the influence of finance on the development of metropolitan freeway systems and the effect of public transit subsidy programs on both system performance and social equity. His research on the demographics of travel behavior have emphasized access-deprived populations, including women, racial-ethnic minorities, the disabled, and the poor. His work in this area also has explored the relationships between transportation and urban form, with a focus on commuting and employment access for low-wage workers. Professor Taylor teaches courses in transportation policy and planning and research design. Prior to coming to UCLA in 1994, he was an Assistant Professor in the Department of City and Regional Planning at the University of North Carolina 
at Chapel Hill, and before that a Transportation Analyst with the Metropolitan Transportation Commission in Oakland, California.

Anastasia Loukaitou-Sideris (sideris@ucla.edu) is Professor and Chair of the Department of Urban Planning at UCLA. She holds a doctoral degree in Urban Planning and master's degrees in Architecture and Urban Planning from the University of Southern California. Her area of specialization is urban design and physical and land use planning. She has published extensively on issues of downtown development, inner-city revitalization, transit-oriented design and transit safety, and parks and open spaces. Recent and ongoing projects have been funded by the California Department of Transportation, the California Policy Research Center, the National Endowment for the Arts, the Poverty and Race Research Action Council, and the John Randolph and Dora Haynes Foundation, and the Mineta Transportation Institute. She has served as a consultant to the Transportation Research Board, the Federal Highway Administration, the Southern California Association of Governments, Los Angeles, the Metropolitan Transportation of Authority, the South Bay Cities Council of Government, the Los Angeles Neighborhood Initiative, the Roger Wood Johnson Foundation, the Greek government, and many municipal governments on issues of urban design, land use and transportation. She is the co-author of the book Urban Design Downtown: Poetics and Politics of Form, published by the University of California Press in 1998. 